\title{
Social Play Behavior in Adolescent Rats is Mediated by Functional Activity in Medial Prefrontal Cortex and Striatum
}

\author{
Linda WM van Kerkhof', Ruth Damsteegt', Viviana Trezza ${ }^{1,2}$, Pieter Voorn ${ }^{3}$ and \\ Louk JMJ Vanderschuren*,1,4
}

'Rudolf Magnus Institute of Neuroscience, Department of Neuroscience and Pharmacology, University Medical Centre Utrecht, Utrecht, The Netherlands; ${ }^{2}$ Department of Biology, University 'Roma Tre', Rome, Italy; ${ }^{3}$ Department of Anatomy and Neurosciences, Neuroscience Campus Amsterdam, VU University Medical Centre, Amsterdam, The Netherlands; ${ }^{4}$ Department of Animals in Science and Society, Division of Behavioural Neuroscience, Faculty of Veterinary Medicine, Utrecht University, Utrecht, The Netherlands

\begin{abstract}
Social play behavior is a characteristic, vigorous form of social interaction in young mammals. It is highly rewarding and thought to be of major importance for social and cognitive development. The neural substrates of social play are incompletely understood, but there is evidence to support a role for the prefrontal cortex (PFC) and striatum in this behavior. Using pharmacological inactivation methods, ie, infusions of GABA receptor agonists (baclofen and muscimol; B\&M) or the AMPA/kainate receptor antagonist 6,7-dinitroquinoxaline2,3(IH,4H)-dione (DNQX), we investigated the involvement of several subregions of the medial PFC and striatum in social play. Inactivation of the prelimbic cortex, infralimbic cortex, and medial/ventral orbitofrontal cortex using B\&M markedly reduced frequency and duration of social play behavior. Local administration of DNQX into the dorsomedial striatum increased the frequency and duration of social play, whereas infusion of B\&M tended to have the same effect. Inactivation of the nucleus accumbens (NAcc) core using B\&M increased duration but not frequency of social play, whereas B\&M infusion into the NAcc shell did not influence social play behavior. Thus, functional integrity of the medial PFC is important for the expression of social play behavior. Glutamatergic inputs into the dorsomedial striatum exert an inhibitory influence on social play, and functional activity in the NAcc core acts to limit the length of playful interactions. These results highlight the importance of prefrontal and striatal circuits implicated in cognitive control, decision making, behavioral inhibition, and reward-associated processes in social play behavior.
\end{abstract}

Neuropsychopharmacology (2013) 38, I899-1909; doi:I0.1038/npp.2013.83; published online I May 2013

Keywords: social play behavior; adolescence; prefrontal cortex; dorsal striatum; nucleus accumbens; AMPA receptors

\section{INTRODUCTION}

Substantial changes in brain and behavior occur between weaning and early adulthood. For example, there is a marked increase in peer-peer interactions, signified by an abundance of social play behavior, which peaks during the juvenile/early adolescent phase and declines to low levels after sexual maturation (Panksepp, 1981). Proper social interactions during this phase of life are thought to be important for social and cognitive development (Pellis and Pellis, 2009; Špinka et al, 2001; Vanderschuren et al, 1997). Indeed, social isolation of rats during the juvenile/early adolescent phases produces long-lasting impairments in social capacities and cognitive control of behavior, even after prolonged re-socialization (van den Berg et al, 1999; Baarendse et al, 2013), and social traumas during childhood

*Correspondence: Professor LJMJ Vanderschuren, Department of Animals in Science and Society, Division of Behavioural Neuroscience, Faculty of Veterinary Medicine, Utrecht University, Yalelaan 2, Utrecht 3584 CM, The Netherlands, Tel: +31 30 2535239, Fax: +31 30 2537997, E-mail: I.j.m.j.vanderschuren@uu.nl Received 7 December 2012; revised 29 March 2013; accepted 3 April 2013; accepted article preview online 8 April 2013 and adolescence can increase the risk for psychopathology in later life (Braun and Bock, 2011). Likewise, abnormalities in social play behavior are observed in childhood psychiatric disorders such as autism and attention deficit/ hyperactivity disorder (Alessandri, 1992; Manning and Wainwright, 2010). Therefore, identifying the neural underpinnings of social play behavior will increase our understanding of normal social development as well as of the etiology of childhood and adolescent psychiatric disorders.

Although the neural substrates of social play behavior are incompletely understood (Siviy and Panksepp, 2011; Trezza et al, 2010; Vanderschuren et al, 1997), there is evidence to support a role for the prefrontal cortex (PFC) and striatum in the regulation of social play behavior (Bell et al, 2009; Panksepp et al, 1994; Pellis et al, 1993, 2006; Schneider and Koch, 2005; Trezza et al, 2011, 2012). As it is in these regions that profound neural changes occur during the juvenile and adolescent period (Casey and Jones, 2010; Crone and Dahl, 2012; Spear, 2000), the abundance of social play behavior suggests that play is related to the maturation of the PFC and striatum.

Using c-fos as an activity marker, enhanced neuronal activity has been observed after social play behavior in 
several medial PFC regions, ie, anterior cingulate, prelimbic cortex (PrL) and infralimbic cortex (IL), as well as in orbitofrontal cortex (OFC) regions (Cheng et al, 2008; Gordon et al, 2002; Van Kerkhof et al, 2013). In keeping with these findings, the structure of social play and its sensitivity to social cues was found to be altered after neonatal lesions of the PFC or OFC (Bell et al, 2009; Panksepp et al, 1994; Pellis et al, 2006; Schneider and Koch, 2005).

With regard to the striatum, studies in nonhuman primates found that a larger size of the striatum was associated with more time spent on social play behavior, while there was no correlation with the level of non-social play behavior (Graham, 2011). Recent studies have also indicated a role for the ventral parts of the striatum, ie, nucleus accumbens (NAcc), in the modulation of social play behavior by opioids and endocannabinoids (Trezza et al, 2011, 2012). Furthermore, neonatal dopamine depletion in the striatum caused rats to use less complex defence strategies during a playful encounter and to be more likely to switch to other types of behavior (Pellis et al, 1993). This indicates that striatal dopamine contributes to the maintenance of the sequential organization of play fighting. Interestingly, this somewhat resembles the effect of neonatal lesions of the medial PFC (Bell et al, 2009), suggesting involvement of projections from medial PFC to striatum in social play behavior. Further evidence for an involvement of corticostriatal projections is provided by immediate early gene expression studies, demonstrating that social play behavior induces c-fos expression in the striatum (Cheng et al, 2008; Gordon et al, 2002; Van Kerkhof et al, 2013). Interestingly, the levels of c-fos induced in medial PFC regions were found to correlate with the levels of $\mathrm{c}$-fos in their striatal projection areas, suggesting that these projections are involved in social play behavior (Van Kerkhof et al, 2013).

On the basis of these studies, it is plausible that the PFC and striatum play important roles in the regulation of social play behavior. However, most of these studies used either indirect approaches (Cheng et al, 2008; Gordon et al, 2002; Van Kerkhof et al, 2013) or neonatal lesions (Bell et al, 2009; Panksepp et al, 1994; Pellis et al, 1993, 2006; Schneider and Koch, 2005), which may disrupt normal brain development and/or lead to compensatory changes in non-affected structures. Therefore, here we investigated the role of PFC and striatum subregions in social play behavior using a temporary pharmacological inactivation technique, which allows for transient disruption of functional activity but leaves normal brain development and function intact (Martin, 1991; McFarland and Kalivas, 2001; Van Duuren et al, 2007).

\section{MATERIALS AND METHODS}

\section{Animals}

Male Wistar rats (Charles River, Sulzfeld, Germany) arrived in our animal facility at 21 days of age. They were housed in groups of four in $40 \times 26 \times 20 \mathrm{~cm}^{3}$ Macrolon cages under controlled conditions (ie, temperature $20-21{ }^{\circ} \mathrm{C}, 55-65 \%$ relative humidity and $12 / 12 \mathrm{~h}$ light cycle with lights on at 0700 hours). Food and water were available ad libitum. All animals were experimentally naive. Before the start of the experiment, rats were handled at least twice. All experiments were approved by the Animal Ethics Committee of
Utrecht University and were conducted in accordance with Dutch laws (Wet op de Dierproeven, 1996) and European regulations (Guideline 86/609/EEC).

\section{Surgical Procedures}

The surgical procedures were based on previous experiments (Trezza et al, 2011, 2012). At 27-28 days of age, rats were anesthetized with $0.08 \mathrm{ml} / 100 \mathrm{~g}$ (s.c.) of Hypnorm (Janssen, Belgium) and positioned in a stereotaxic apparatus (David Kopf, USA). Guide cannulae (24 gauge; Cooper's Needleworks, UK) were implanted bilaterally. The cannulae were aimed $0.5 \mathrm{~mm}$ above the $\operatorname{PrL}$ (coordinates: anteriorposterior (AP) $+2.6 \mathrm{~mm}$ from Bregma; medial-lateral (ML) $\pm 0.8 \mathrm{~mm}$ from the midline; dorsal-ventral (DV) $-3.2 \mathrm{~mm}$ from skull surface), the IL (coordinates: AP $+2.6 \mathrm{~mm}$; $\mathrm{ML} \pm 0.8 \mathrm{~mm}$; DV $-4.1 \mathrm{~mm})$, the medial/ventral OFC (MO/VO; coordinates: $\mathrm{AP}+3.3 \mathrm{~mm}$; $\mathrm{ML} \pm 0.8 \mathrm{~mm}$; $\mathrm{DV}$ $-5.3 \mathrm{~mm}$ ), the dorsomedial striatum (DMS; coordinates: $\mathrm{AP}+1.5 \mathrm{~mm}$; $\mathrm{ML} \pm 1.9 \mathrm{~mm}$; DV $-5.1 \mathrm{~mm})$, the NAcc core (coordinates: AP, $+1.5 \mathrm{~mm}$; ML $\pm 1.9 \mathrm{~mm}$; DV $-6.5 \mathrm{~mm}$ ), or $1.0 \mathrm{~mm}$ above the NAcc shell (coordinates: AP $+1.5 \mathrm{~mm}$; $\mathrm{ML} \pm 0.8 \mathrm{~mm} ; \mathrm{DV}-5.3 \mathrm{~mm})$. Coordinates were based on previous experiments (Trezza et al, 2011, 2012) or determined by pilot placements in 4-week-old rats.

Cannulae were secured with stainless steel screws and dental acrylic. Stainless steel stylets (29 gauge) were inserted into the guide cannulae to maintain patency. After surgery, rats were individually housed for 4 days to recover, after which they were housed with their original cage mates.

\section{Drugs and Infusion Procedures}

The GABA-A receptor agonist muscimol and the GABA-B receptor agonist (RS)-baclofen (Tocris Bioscience, UK) were dissolved in saline. In all regions $1.0 \mathrm{nmol} / 0.3 \mu \mathrm{l}$ baclofen and $0.1 \mathrm{nmol} / 0.3 \mu \mathrm{l}$ muscimol (B\&M) was administered, with the exception of the NAcc shell into which $0.1 \mathrm{nmol} / 0.3 \mu \mathrm{l}$ baclofen and $0.01 \mathrm{nmol} / 0.3 \mu \mathrm{l}$ muscimol was infused. Lower doses of B\&M were infused into the NAcc shell because the $1.0 \mathrm{nmol}$ baclofen/0.1 nmol muscimol dose caused intense, non-specific hyperphagia (see eg, Stratford and Kelley, 1997), which resulted in a complete blockade of social play. The AMPA/kainate receptor antagonist, 6,7-dinitroquinoxaline-2,3(1H,4H)-dione (DNQX) (Sigma, USA), was dissolved in $50 \%$ DMSO in saline, and a dose of $3.0 \mathrm{nmol} / 0.3 \mu \mathrm{l}$ was administered. Infusion procedures were as previously described (Trezza et al, 2011, 2012). In short, bilateral infusions of drugs or equivalent volume of saline were administered using 30-gauge injection needles (Bilaney, Germany) connected to $10 \mu \mathrm{l}$ Hamilton micro-syringes by polyethylene tubing. Over $60 \mathrm{~s}, 0.3 \mu \mathrm{l}$ of the solution was infused using a syringe pump (Harvard Apparatus, USA). The injection needles remained within the guide cannulae for $60 \mathrm{~s}$ following drug infusion to facilitate diffusion and to prevent backflow of drug along the cannula track. After the infusion, the stylets were replaced.

\section{Behavioral Testing}

Experiments were performed in a sound-attenuated chamber under dim light conditions. The testing arena 
was a Plexiglas cage $\left(40 \times 40 \times 60 \mathrm{~cm}^{3}\right)$, with approximately $2 \mathrm{~cm}$ of wood shavings covering the floor. Animals were paired with an unfamiliar partner (ie, not a cage mate). Animals in a test pair did not differ $>10 \mathrm{~g}$ in body weight.

One week after surgery, the rats were habituated to the experimental procedures on 2 consecutive days. On the first day, they were individually placed in the test cage for $10 \mathrm{~min}$. On the second day, they were isolated for $2.5 \mathrm{~h}$. Pairs of rats were then infused with saline and placed together in the test cage for $15 \mathrm{~min}$ to habituate them to the infusion and testing procedures. On the test day, rats were again isolated for $2.5 \mathrm{~h}$. Both rats in a pair were then simultaneously infused, placed into separate holding cages for $5 \mathrm{~min}$, and subsequently placed together into the test cage for $15 \mathrm{~min}$.

Behavior of the animals was recorded on video tape and subsequently assessed using the Observer software (Noldus Information Technology, The Netherlands) by an observer blind to treatment. The structure of social play behavior in rats has been previously described in detail (Baenninger, 1967; Bolles and Woods, 1964; Panksepp and Beatty, 1980; Pellis and Pellis, 1987; Pellis et al, 1989; Poole and Fish, 1975; for reviews, see Panksepp et al, 1984; Pellis and Pellis, 1998; Trezza et al, 2010; Vanderschuren et al, 1997). In rats, a bout of social play behavior starts with one rat soliciting ('pouncing') another animal, by attempting to nose or rub the nape of its neck. The animal that is pounced upon can respond in different ways. If the animal that is pounced upon responds by evading, the soliciting rat may start to chase it, thus making another attempt to launch a play bout. The solicited animal may also rear towards the soliciting animal and the two animals may rapidly push, paw, and grab each other ('boxing'). If the animal that is pounced upon fully rotates to its dorsal surface, 'pinning' is the result, ie, one animal lying with its dorsal surface on the floor with the other animal standing over it. From this position, the supine animal can initiate another play bout, by trying to gain access to the other animal's neck. Thus, during social play, pouncing is considered an index of play solicitation, while pinning functions as a releaser of a prolonged play bout (Panksepp and Beatty, 1980; Pellis and Pellis, 1987; Pellis et al, 1989; Poole and Fish, 1975). Pinning and pouncing frequencies can be easily quantified and are considered the most characteristic parameters of social play behavior in rats (Panksepp and Beatty, 1980). During the social encounter, animals may also display social behaviors not directly associated with play, such as sniffing or grooming the partner's body (Panksepp and Beatty, 1980; Vanderschuren et al, 1995). As social play behavior in rats strongly depends on the playfulness of its partner (Pellis and McKenna, 1992; Trezza and Vanderschuren, 2008), in the present study, both animals in a play pair were similarly treated and a pair of animals was considered as one experimental unit. The following parameters were therefore scored per pair of animals:

Social behaviors related to play:

- Frequency of pinning

- Frequency of pouncing

- Total play duration: the total amount of time spent in playful social interactions (ie, pinning, pouncing, boxing, or chasing the play partner).
Social behaviors unrelated to play:

- Time spent in social exploration: the total amount of time spent in non-playful forms of social interaction (ie, one animal sniffing or grooming any part of the partner's body).

Pinning, pouncing, and other playful behaviors usually occur very rapidly and they are of short duration. Therefore, scoring their individual frequency is more informative than scoring their duration. Moreover, we have also found that pinning and pouncing are very reliable play parameters that occur consistently and with considerable frequency during playful encounters (see also Panksepp and Beatty, 1980; Vanderschuren et al, 1995), whereas the occurrence of chasing and boxing can be quite variable. In order to evaluate the amount of time spent in playful social behaviors (eg, pinning, pouncing) vs social behaviors unrelated to play (eg, social exploration: sniffing, social grooming), we included the total play duration as a parameter as well. Changes in boxing and chasing provided only minor contributions to the effects on total play duration observed (data not shown).

To assess whether effects of the drug treatment on social play were secondary to changes in locomotor activity, rats (at 41 days of age) were tested for horizontal locomotor activity as described previously (Trezza et al, 2009; Veeneman et al, 2011). Between the test for social play behavior and locomotor activity, there was at least one day without testing or infusions. The infusion protocol was as described above. After infusion, the rats were transferred to a plastic cage $\left(1 \times \mathrm{w} \times \mathrm{h}, 50 \times 33 \times 40 \mathrm{~cm}^{3}\right)$, and their position was tracked five times per second for 30 min using a video-tracking system (EthoVision, Noldus Information Technology, The Netherlands).

\section{Histological Confirmation of Injection Sites}

Confirmation of the injection sites was performed as previously described (Trezza et al, 2011, 2012). Only pairs of rats in which both animals had bilateral needle tracks terminating in the target area were included in the final analysis (Figure 1).

\section{Statistical Analysis}

Pinning and pouncing frequencies, total play duration (s), and time spent in social exploration (s) were expressed as mean \pm SEM, and data were analyzed using a paired samples Student's $t$-test. Horizontal locomotor activity was expressed as mean \pm SEM of the travelled distance $(\mathrm{cm})$ and analyzed using a two-way repeated-measures ANOVA.

\section{RESULTS}

\section{Pharmacological Inactivation of Prefrontal Regions}

Infusion of B\&M into the PrL decreased social play behavior (Figure 2). The frequencies of pinning (Figure 2a) and pouncing (Figure 2b) and total play duration (Figure 2c) were reduced (pinning: $t=3.145, \mathrm{df}=8, \mathrm{p}=0.014$; pouncing: $t=3.509, \mathrm{df}=8, p=0.008$; total play: $t=2.734, \mathrm{df}=8$, 

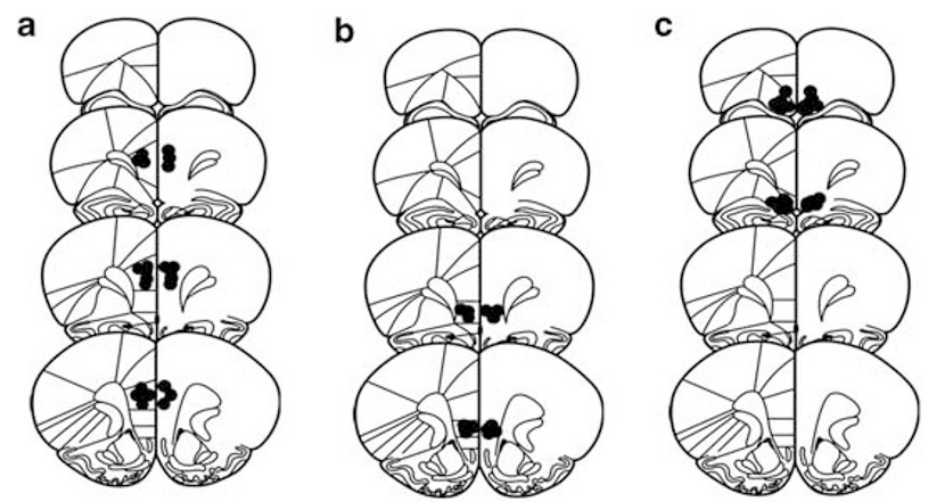

$A P+4.20$

$A P+3.70$

$\mathrm{AP}+3.20$
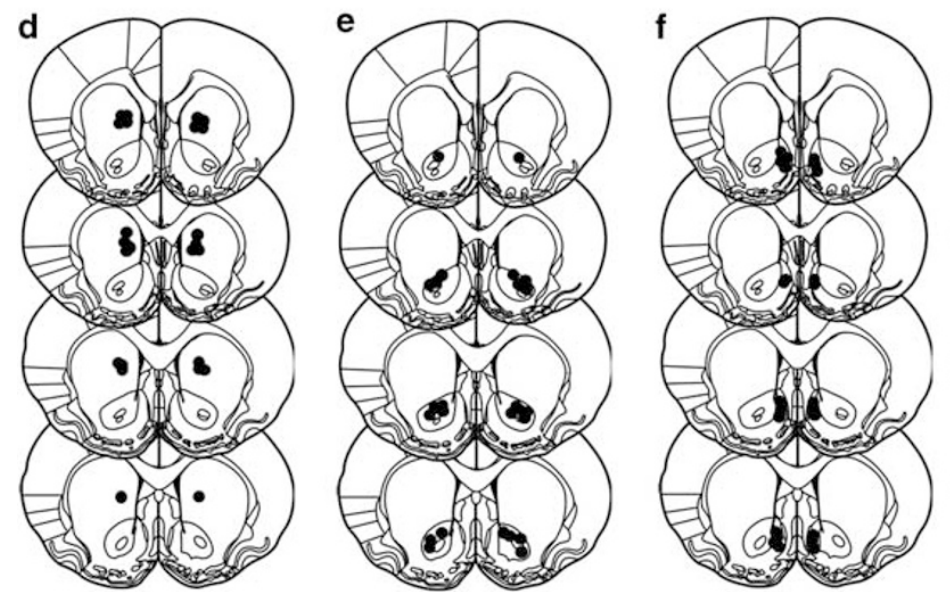

$\mathrm{AP}+2.70$

$A P+1.70$

$A P+1.60$

$A P+1.20$

$A P+1.00$

Figure I Schematic representation of brain sections with microinjection placements in the prelimbic cortex (a), infralimbic cortex (b), medial/ventral orbitofrontal cortex (c), dorsomedial striatum (d), nucleus accumbens core (e), and nucleus accumbens shell (f). AP, distance anterior to Bregma (in mm). Adapted from Paxinos and Watson (2007).

$p=0.026)$. The duration of social exploration was increased $(t=-2.322, \mathrm{df}=8, p=0.049 ;$ Figure $2 \mathrm{~d})$, whereas no change was observed in locomotor activity $\left(F_{\text {treatment }}\right.$ $(1,23)=0.801, \quad p=0.380 ; \quad F_{\text {time }}(5,115)=66.445, \quad p<0.001 ;$ $\mathrm{F}_{\text {treatment } \times \text { time }}(5,115)=0.177, p=0.971$; Figure $\left.2 \mathrm{e}\right)$.

After administration of B\&M into the IL, a decrease in pinning, pouncing, and total play duration was observed (pinning: $t=4.616, \mathrm{df}=7, p=0.002$; pouncing: $t=5.285$, $\mathrm{df}=7, \quad p=0.001$; total play duration: $t=4.420, \mathrm{df}=7$, $p=0.003$; Figure $2 \mathrm{f}-\mathrm{h}$ ). Comparable with the PrL, infusion of B\&M into the IL tended to increase social exploration $(t=-2.105, \mathrm{df}=7, p=0.073$; Figure 2i) but did not alter locomotor activity $\left(\mathrm{F}_{\text {treatment }}(1,18)=0.817, \quad p=0.378\right.$; $\mathrm{F}_{\text {time }}(5,90)=57.835, p<0.001 ; \mathrm{F}_{\text {treatment } \times \text { time }}(5,90)=0.223$, $p=0.952$; Figure $2 \mathrm{j}$ ).

Administration of $\mathrm{B} \& \mathrm{M}$ into the $\mathrm{MO} / \mathrm{VO}$ resulted in a decrease in pinning, pouncing, and total play duration (pinning: $t=4.408, \mathrm{df}=5, p=0.007$; pouncing: $t=4.146$, $\mathrm{df}=5, p=0.009$; total play duration: $t=4.190, \mathrm{df}=5$, $p=0.009$; Figure $2 \mathrm{k}-\mathrm{m}$ ), whereas no effects were observed on social exploration (Figure $2 \mathrm{n}$ ) or locomotor activity (Figure 2o; social exploration: $t=-0.384, \mathrm{df}=5, p=0.717$; locomotor activity: $\mathrm{F}_{\text {treatment }}(1,15)=0.160, \quad \mathrm{p}=0.695$; $\mathrm{F}_{\text {time }}(5,75)=36.445, p<0.001 ; \mathrm{F}_{\text {treatment } \times \text { time }}(5,75)=0.354$, $p=0.878)$.

The effect size of the changes in pinning, pouncing, and total play duration (ie, percentage of decrease compared with saline) were comparable in the three regions (pinning: PrL: $-41.14 \pm 10.45$; IL: $-57.47 \pm 12.01$; MO/ VO: $-50.80 \pm 8.65$; pouncing: PrL: $-32.51 \pm 8.46$; IL: $-55.29 \pm 8.23$; MO/VO: $-40.33 \pm 8.26$; total play duration: PrL: $\quad-32.72 \pm 10.14$; IL: $\quad-49.91 \pm 13.56$; MO/VO: $-43.46 \pm 8.73)$. No difference was observed when the reduction in pinning, pouncing, or total play duration was compared between the three regions (pinning: $F_{\text {region }}$ $(2,20)=0.633, p=0.541$; pouncing: $\mathrm{F}_{\text {region }}(2,20)=0.2 .338$, $p=0.122$; total play duration $\left(\mathrm{F}_{\text {region }}(2,20)=0.621\right.$, $p=0.548)$.

\section{Pharmacological Inactivation of Striatal Regions}

Administration of $B \& M$ into the DMS did not affect pinning $(t=-1.726, \mathrm{df}=12, p=0.110$; Figure $3 \mathrm{a})$, but a trend towards an increase in the frequency of pouncing was observed $(t=-2.168, \mathrm{df}=12, p=0.051$; Figure $3 \mathrm{~b})$. Treatment with $\mathrm{B} \& \mathrm{M}$ also tended to decrease social exploration $(t=2.126, \mathrm{df}=12, p=0.055$; Figure $3 \mathrm{~d})$, but it did not affect total play duration $(t=-1.214, \mathrm{df}=12, \quad p=0.248$; Figure $3 c)$ or locomotor activity $\left(F_{\text {treatment }}(1,17)=0.512\right.$, $p=0.484 ; \quad F_{\text {time }}(5,85)=24.767, \quad p<0.001 ; \quad F_{\text {treatment } \times \text { time }}$ $(5,85)=0.684, p=0.637$; Figure $3 e)$.

Although infusion of B\&M into the NAcc core did not influence pinning $(t=-1.138, \mathrm{df}=10, p=0.281)$ or pouncing frequencies $(t=-0.278, \mathrm{df}=10, \quad p=0.787)$ 

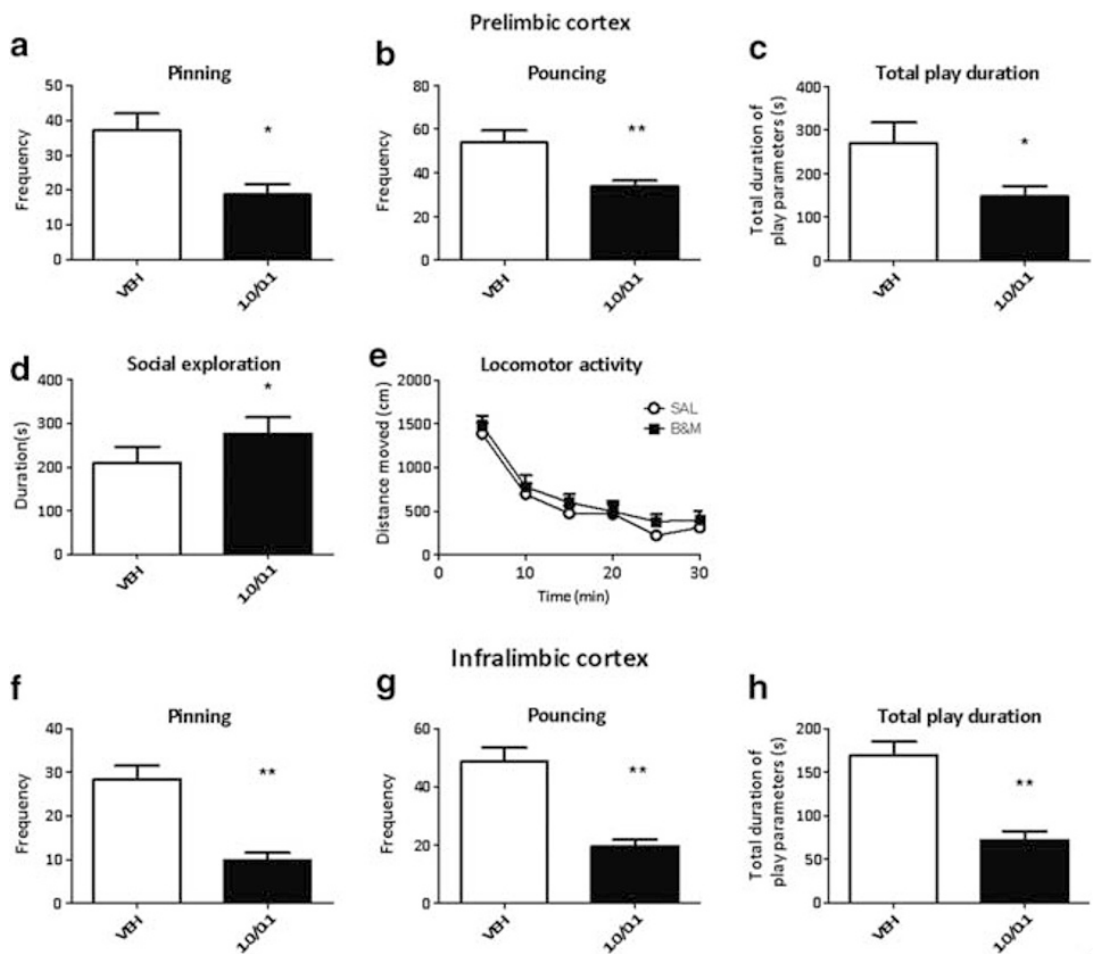

h
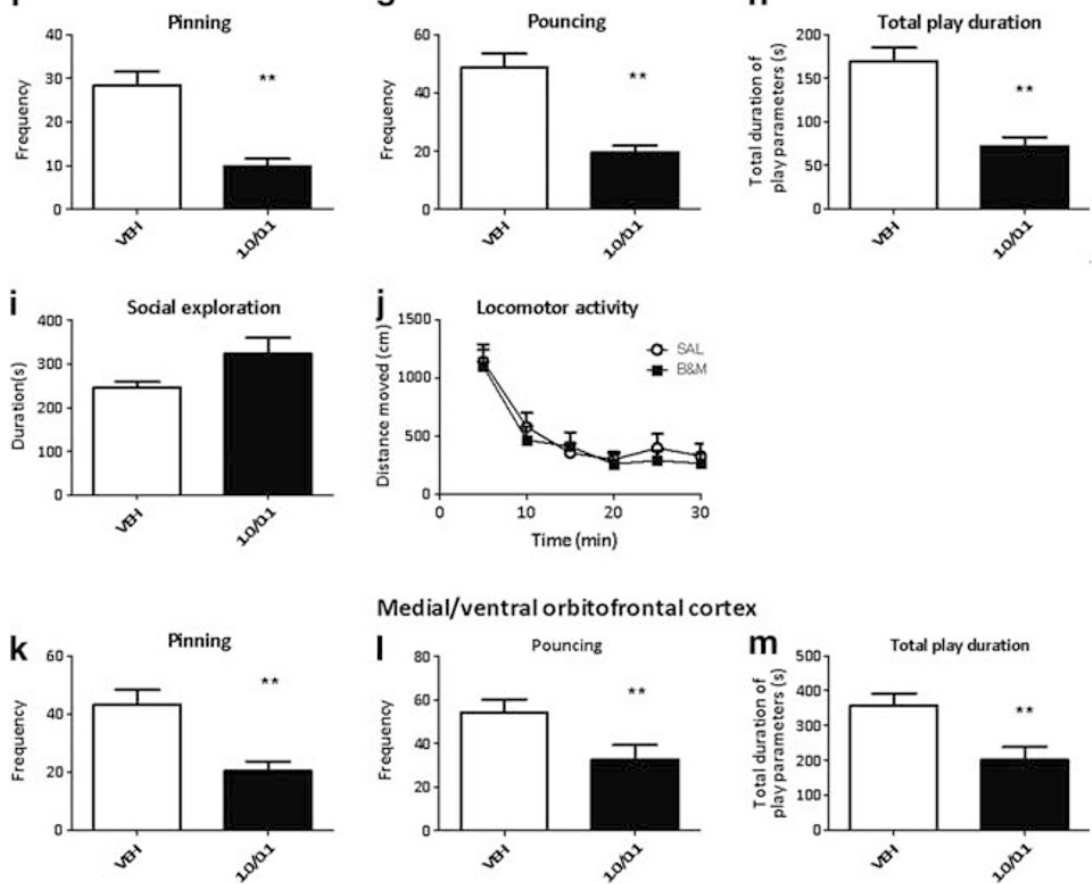

Medial/ventral orbitofrontal cortex
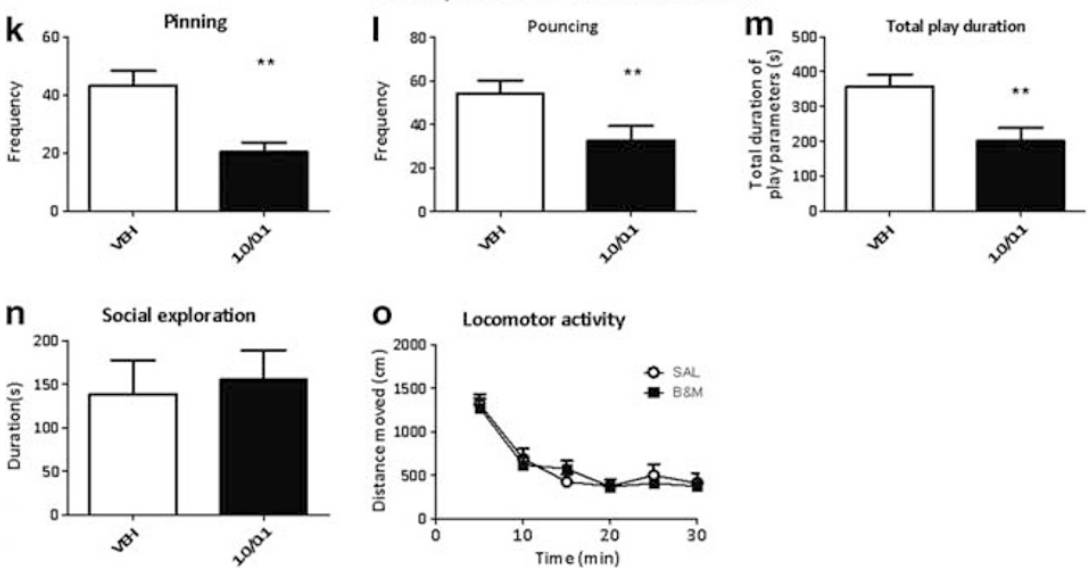

Figure 2 The effect of B\&M administration $(1.0 \mathrm{nmol} / 0.3 \mu \mathrm{l}$ and $0.1 \mathrm{nmol} / 0.3 \mu \mathrm{l})$ into prefrontal regions on social play behavior. Data are presented as mean \pm SEM. B\&M administration into the prelimbic cortex $(n=9)$ reduced the levels of pinning $(a)$ and pouncing $(b)$, as well as the total time spent on play (c). B\&M administration increased the time spent on social exploration (d), whereas it had no effect on locomotor activity (e). Infusion of B\&M into the infralimbic cortex $(n=8)$ reduced the levels of pinning $(f)$, pouncing $(g)$, and the total time spent on play $(h)$, whereas no effects were observed on social exploration (i) or locomotor activity (j). After administration of B\&M into the medial/ventral orbitofrontal cortex $(n=6)$, a reduction in pinning $(k)$, pouncing $(\mathrm{I})$, and the total time spent on play was observed $(\mathrm{m})$, whereas no effect on social exploration $(\mathrm{n})$ or locomotor activity $(0)$ was found. * $p<0.05$, $* * * 0.0 \mathrm{I}$ compared with saline (SAL; paired samples Student's t-test).

(Figure $3 \mathrm{f}-\mathrm{g}$ ), it did increase the total time spent on social play behavior $(t=-2.733, \mathrm{df}=10, p=0.021$; Figure $3 \mathrm{~h})$, suggesting that the duration of play bouts was enhanced. Administration of B\&M into the NAcc core had no effect on social exploration $(t=-0.916, \mathrm{df}=10, p=0.381$; Figure $3 \mathrm{i})$ or locomotor activity $\left(F_{\text {treatment }}(1,13)=0.462, p=0.509\right.$; $\mathrm{F}_{\text {time }}(5,65)=47.795, p<0.001 ; \mathrm{F}_{\text {treatment } \times \text { time }}(5,65)=0.220$, $p=0.953$; Figure $3 \mathrm{j})$. 

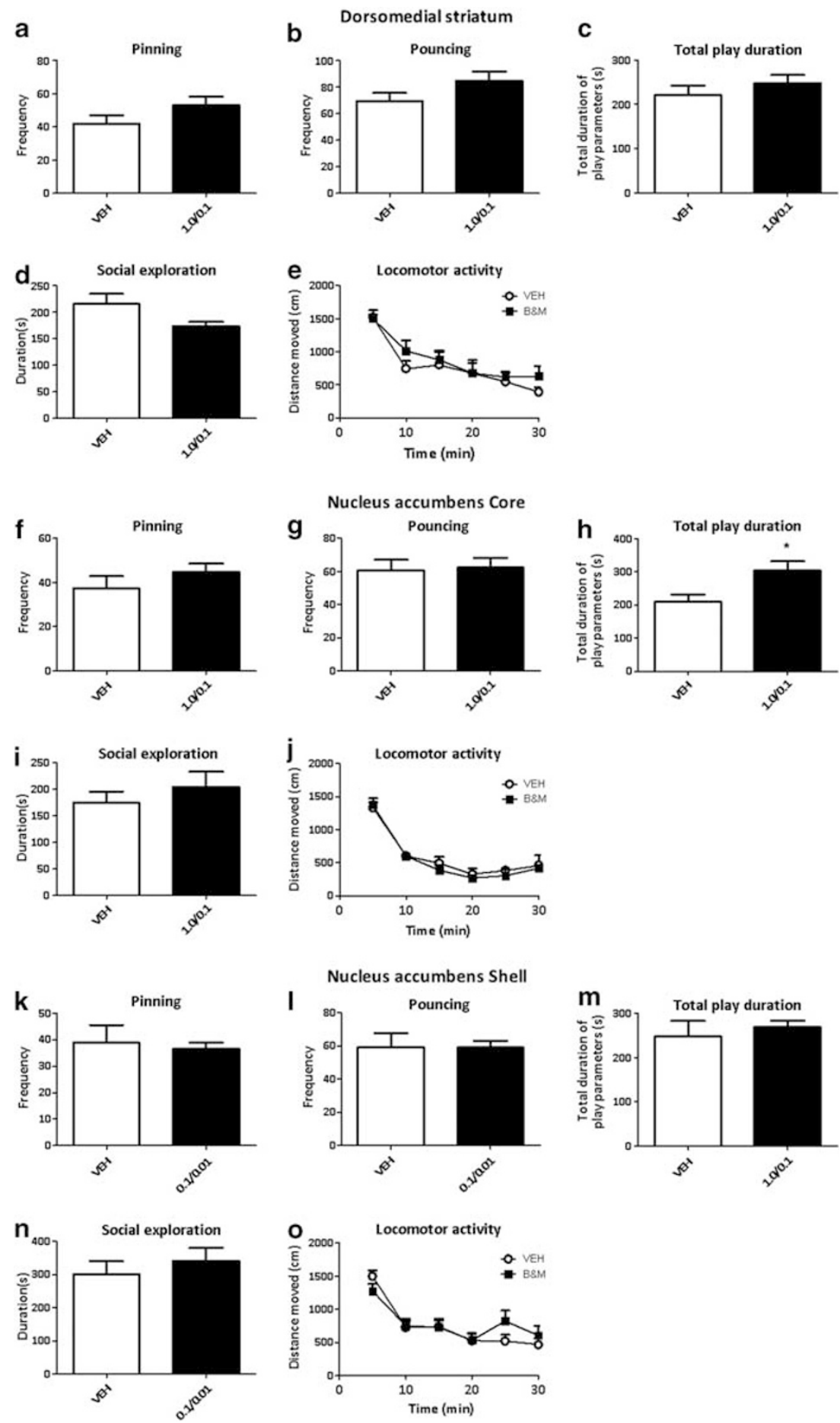

Figure 3 The effect of B\&M administration into striatal regions on social play behavior. Data are presented as mean \pm SEM. B\&M was administered into the dorsomedial striatum (a-e;n=13) and nucleus accumbens core $(\mathrm{f}-\mathrm{j} ; n=10)$ in a dose of $1.0 \mathrm{nmol} / 0.3 \mu \mathrm{l}$ and $0.1 \mathrm{nmol} / 0.3 \mu \mathrm{l}$ and into the nucleus accumbens shell $(k-p ; n=5)$ ) in a dose of 0.1 nmol/ $0.3 \mu l$ and 0.01 nmol/ $0.3 \mu l$. Administration of B\&M did not affect pinning (a,f,k), pouncing $(b, g, l)$, social exploration (d,i,n), and locomotor activity (e,j,po), although in the dorsomedial striatum a trend towards an increase in pouncing ( $p=0.05 \mathrm{I} ; \mathrm{b})$ and a trend towards a reduction in the time spent on social exploration $(p=0.055 ; d)$ was found. The total time spent on social play behavior was increased after B\&M administration into the nucleus accumbens core (h), but not after administration into the dorsomedial striatum (c) or nucleus accumbens shell $(\mathrm{m})$. $* p<0.05$ compared with vehicle (VEH; paired samples Student's t-test).

Administration of $\mathrm{B} \& \mathrm{M}$ at the dose used in the other regions $(1.0 \mathrm{nmol}$ baclofen and $0.1 \mathrm{nmol}$ muscimol/ $/ 0.3 \mu \mathrm{l})$ into the NAcc shell resulted in a complete blockade of play (data not shown), which was secondary to striking effects on ingestive behavior. Animals would spend all their time on non-specific eating (eating eg, sawdust and faeces; see Stratford and Kelley, 1997). Therefore, a lower dose of B\&M $(0.1 \mathrm{nmol}$ baclofen and $0.01 \mathrm{nmol}$ muscimol/ $/ 0.3 \mu \mathrm{l})$, which had no general disruptive effects on behavior was administered into the NAcc shell. This dose had no effect on any of 

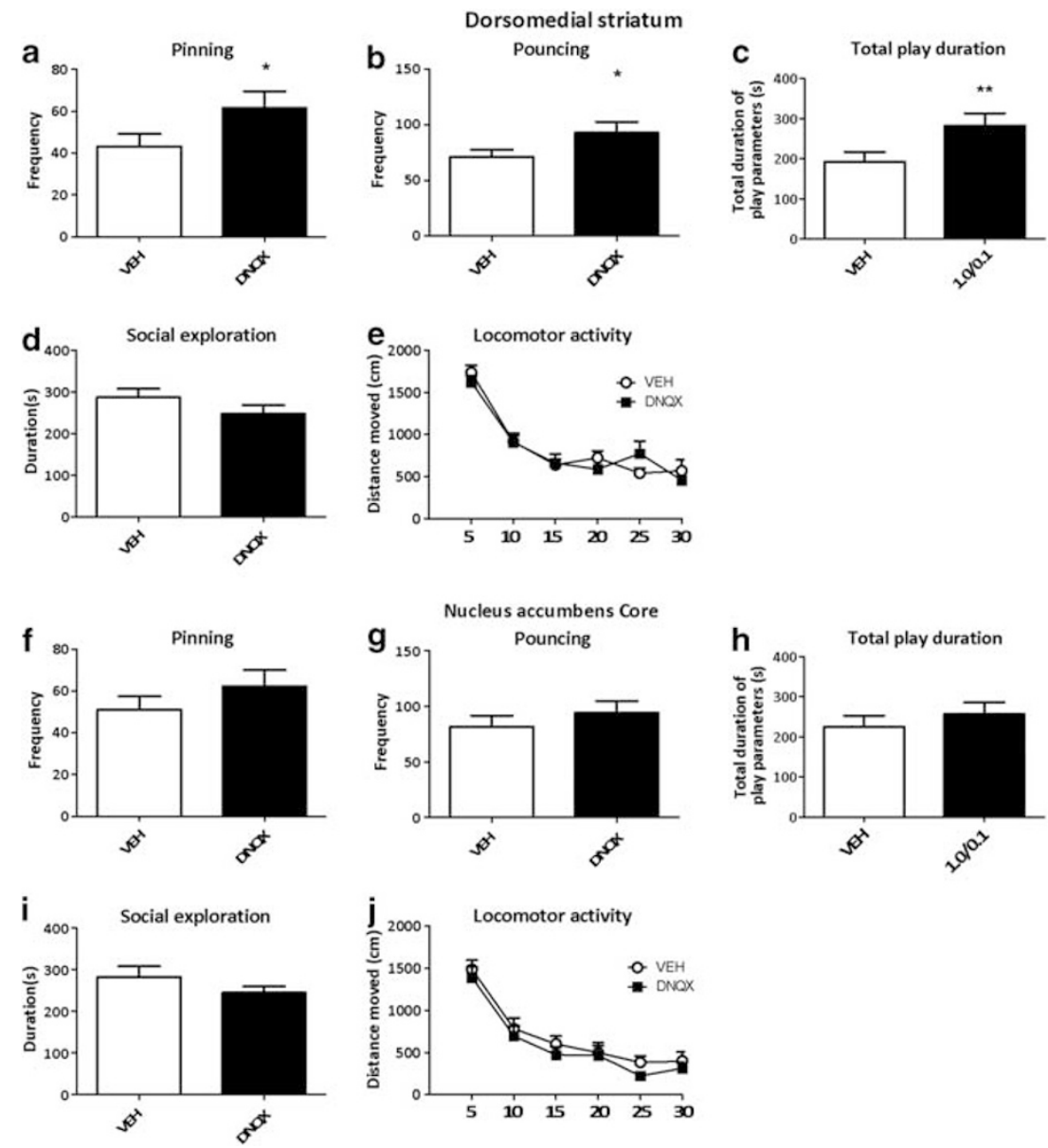

Figure 4 The effect of DNQX administration $(3.0 \mathrm{nmol} / 0.3 \mu \mathrm{l})$ into the dorsomedial striatum and nucleus accumbens core on social play behavior. Data are presented as mean \pm SEM. DNQX administration into the dorsomedial striatum $(n=9)$ increased the frequency of pinning $(a)$, pouncing $(b)$, and the total time spent on play behavior (c), whereas it did not affect the time spent on social exploration (d) or locomotor activity (e). Infusion of B\&M into the nucleus accumbens core $(n=8)$ did not change the level of pinning (f), pouncing (g), total play duration (h), social exploration (i), or locomotor activity (j). ${ }^{*} p<0.05, * * * 0.0$ I compared with vehicle (VEH; paired samples Student's t-test).

the parameters measured (pinning: $t=0.353, \mathrm{df}=4$, $p=0.742$; pouncing: $t=0.105, \mathrm{df}=4, p=0.922$; total play duration: $t=-0.263$, $\mathrm{df}=4, p=0.806$; social exploration: $t=-0.683, \mathrm{df}=4, p=0.532$; locomotor activity: $\mathrm{F}_{\text {treatment }}$ $(1,13)=0.113, \quad p=0.742 ; \quad \mathrm{F}_{\text {time }}(5,65)=31.444, \quad p<0.001$; $\mathrm{F}_{\text {treatment } \times \text { time }}(5,65)=2.342, p=0.051$; Figure $\left.3 \mathrm{k}-\mathrm{o}\right)$.

\section{Involvement of Glutamatergic Input to the Striatum}

In view of the effects of $B \& M$ in the prefrontal regions and the striatum (with an effect in the NAcc core and a trend in the DMS), and the glutamatergic projections from the PFC to the striatum (Groenewegen and Uylings, 2010; Voorn et al, 2004), the role of glutamatergic input into the striatum in social play was investigated using intra-striatal administration of the AMPA receptor antagonist DNQX. Administration of DNQX into the DMS specifically influenced social play behavior, as it increased pinning $(t=-2.552$, $\mathrm{df}=8, p=0.034$; Figure $4 \mathrm{a})$ and pouncing $(t=1.403, \mathrm{df}=8$, $p=0.032$; Figure $4 \mathrm{~b}$ ) frequencies, and total play duration ( $t=-4.035, \mathrm{df}=8, p=0.004$; Figure $4 \mathrm{c}$ ), without affecting social exploration $(t=1.403, \mathrm{df}=8, p=0.198$; Figure $4 \mathrm{~d})$ or locomotor activity $\left(F_{\text {treatment }}(1,18)=0.059, p=0.811\right.$; $\mathrm{F}_{\text {treatment } \times \text { time }}(5,90)=1.395, p=0.234$; Figure $\left.4 \mathrm{e}\right)$.

Infusion of DNQX into the NAcc core did not affect any of the parameters measured (pinning: $t=-1.769, \mathrm{df}=7$ $p=0.120$; pouncing: $t=-1.254$, $\mathrm{df}=7, p=0.250$; total play duration: $t=-0.959, \mathrm{df}=7, p=0.370$; social exploration: $t=1.382, \quad \mathrm{df}=7, \quad p=0.210$; locomotor activity: $\mathrm{F}_{\text {treatment }}(1,17)=0.877, p=0.362 ; \mathrm{F}_{\text {treatment } \times \text { time }}(5,85)=$ $0.182, p=0.969$; Figure $4 \mathrm{f}-\mathrm{j})$. DNQX was not administered into the NAcc shell, as this is known to enhance feeding behavior in a comparable fashion as administration of $\mathrm{B} \& \mathrm{M}$ into this region (Maldonado-Irizarry et al, 1995).

\section{DISCUSSION}

\section{Importance of the PFC for Social Play Behavior}

Temporary inactivation of the medial PFC regions reduced the frequency of the most characteristic play parameters in rats, ie, pinning and pouncing, as well as the total time spent on social play behavior, without altering locomotor activity. Inactivation of the PrL, and to a lesser extent the IL, but not the $\mathrm{MO} / \mathrm{VO}$, increased the time the animals spent on social 
behaviors unrelated to play, such as social grooming or sniffing. Combined, the reductions in pouncing (ie, play initiation), pinning (a response to pouncing) as well as total time spent playing, indicates that temporary inactivation of medial PFC regions caused a decrease in social playfulness and that this is not the result of a general decrement in social interest or an overall disruption of behavior. Interestingly, the increase in social exploration after inactivation of the PrL and IL (even though the effect in the IL did not reach statistical significance) suggests that the initiation of social behavior was intact but that this was less often followed by the launch of a playful interaction, which indirectly resulted in an increase in social exploration. Together, these data therefore suggest that functional activity of the medial PFC serves to facilitate playful initiatives.

Altered responses to play initiations have previously been reported after neonatal PFC lesions (Bell et al, 2009; Panksepp et al, 1994; Pellis et al, 2006; Schneider and Koch, 2005). Lesions of the lateral and ventral OFC have been found to disrupt the partner-related modulation of play (Pellis et al, 2006). Thus, control but not lesioned rats respond differently to dominant, subordinate, and female rats. Animals with medial PFC lesions still show partnerrelated changes in social play behavior, but they use less complex defensive strategies (Bell et al, 2009). These, and other, studies indicate that after neonatal PFC lesions, play behavior is still observed but that its structure and sensitivity to social cues is altered (Bell et al, 2009; Panksepp et al, 1994; Pellis et al, 2006; Schneider and Koch, 2005). In the present study, however, the effect of temporary PFC inactivation was more substantial and, in contrast to the neonatal lesion studies, play initiations (ie, pouncing) were markedly reduced.

The methodological approach of the aforementioned lesion studies differs in several respects from the present study. Relatively large lesions were made at an early age (postnatal days 3-7), which may have impaired brain development and damaged fibres of passage. Conversely, after neonatal lesions, other regions may compensate for the loss of function. By contrast, local administration of GABA receptor agonists, as used here, temporarily reduces regional output without affecting brain development and connectivity (Martin, 1991; McFarland and Kalivas, 2001; van Duuren et al, 2007). Hence, our data show that disruption of medial PFC signalling markedly interferes with the expression of social play behavior, indicating that functional integrity of the medial PFC is required for social play behavior.

In the present study, comparable effects of inactivation were observed in the three PFC regions tested. Muscimol administration into a certain cortical region may influence neuronal activity in adjacent regions through local corticocortical circuits (Martin, 1991). However, if in the present study the effects of $B \& M$ in some regions were mediated via cortico-cortical interactions, the behavioral effects would have to be distance-dependent. As no difference was observed in the effect size between the PFC regions, we conclude that each of the three $\mathrm{PFC}$ regions has an important role in social play behavior.

The PFC and OFC have been widely implicated in executive functions, such as attention, planning, cognitive flexibility, and decision making (Dalley et al, 2004; Wallis,
2007). Given the complex and unpredictable nature of social interactions, it is likely that frontal cortical regions subserve executive functions in social situations as well (Adolphs, 2003). Inactivation of the PrL, IL, and MO/VO may, therefore, disrupt social play behavior by interfering with cognitive flexibility and decision-making processes necessary for a proper social interaction. Studies in the past decade have found considerable anatomical (Groenewegen and Uylings, 2010; Hoover and Vertes, 2011; Vertes, 2004) and functional heterogeneity within the PFC and OFC (Chudasama et al, 2003; Gourley et al, 2010; Killcross and Coutureau, 2003; Mar et al, 2011; Peters et al, 2009). This begs the question of the exact contribution of PrL, IL, and $\mathrm{MO} / \mathrm{VO}$ in social play behavior, given that their inactivation produces comparable reductions in social play. Interestingly, cellular activation studies have found similar patterns of activity of PrL and IL neurons during social behavior in late adolescent rats (Wall et al, 2012) and during sexual behavior in adult rats (Balfour et al, 2006). Consistent with this, we have recently found comparable increases in c-fos expression in PrL, IL, MO, and VO after social play, although the magnitude of the effect differed somewhat between these regions (Van Kerkhof et al, 2013). These studies, together with the present data, suggest that these prefrontal subregions have comparable roles in social interactions, even though their contribution to non-social cognitive functions is clearly distinct. How these dissociable cognitive functions of PFC subregions map onto comparable contributions to social interaction is an important topic for future studies.

\section{Inactivation of the NAcc Core Enhances the Duration of Social Play Behavior}

Previous findings have implicated the NAcc in social play behavior (Gordon et al, 2002; Trezza et al, 2011, 2012; Van Kerkhof et al, 2013). Thus, after social play behavior, c-fos activity was enhanced in the NAcc core and shell (Gordon et al, 2002; Van Kerkhof et al, 2013). In addition, the playenhancing effects of mu-opioid receptor agonists and cannabinoid agonists were found to be exerted within the NAcc (Trezza et al, 2011, 2012). In view of the involvement of the NAcc in hedonics and incentive motivation (Berridge and Kringelbach, 2008; Kelley, 2004; Salamone and Correa, 2012), these findings suggest a role for the NAcc in the positive emotional properties of social play behavior. Indeed, blockade of NAcc mu-opioid receptors prevented the development of social play-induced conditioned place preference (Trezza et al, 2011).

Administration of $\mathrm{B} \& \mathrm{M}(1.0 \mathrm{nmol} / 0.3 \mu \mathrm{l}$ and $0.1 \mathrm{nmol} /$ $0.3 \mu \mathrm{l}$ ) into the NAcc shell resulted in a complete blockade of play. This effect was secondary to intense hyperphagia, leaving no opportunity for the animals to engage in social interaction (see Stratford and Kelley, 1997). A lower dose of $B \& M$, which did not induce eating, did not alter social play. As the effects of NAcc shell infusions of GABA receptor agonists and AMPA receptor antagonists on ingestive behavior are highly comparable (Maldonado-Irizarry et al, 1995; Stratford and Kelley, 1997), the effect of intra-shell DNQX infusion on social play was therefore not investigated. Thus, understanding the involvement of NAcc shell function in social play behavior remains difficult. 
Administration of B\&M into the NAcc core enhanced the time spent on social play behavior, but not the frequency of any of the play parameters, indicating that after NAcc core inactivation, the length of a play bout is enhanced. This effect was not observed after administration of DNQX into the NAcc core, which suggests that blocking only glutamatergic inputs into the NAcc core is not sufficient to alter play duration. The facilitatory effect of intra-NAcc core B\&M on social play resonates well with the notion of reduced NAcc neuronal activity during reward-related behavior (Carlezon and Thomas, 2009). Consistent with this idea, it has been shown that firing in a subset of NAcc neurons is suppressed to support the maintenance of appetitive behavior (Taha and Fields, 2006; Krause et al, 2010). Infusion of B\&M into the NAcc core may inhibit these neurons, permitting the prolongation of social play. Consistent with this, lesions of the NAcc core have been shown to enhance the relative rewarding value of social behavior compared with cocaine, as studied using concurrent social behavior vs cocaineinduced conditioned place preference (Fritz et al, 2011).

\section{Glutamatergic DMS Inputs Inhibit Social Play Behavior}

Administration of DNQX into the DMS selectively increased social play behavior, as it enhanced pinning, pouncing, and total play duration, without affecting social exploration or locomotor activity. This pattern of effects, ie, increases in play initiation, responding to initiation as well as total time spent playing, suggests that blockade of AMPA/kainate receptors in the DMS specifically enhanced playful social behavior. Thus, glutamatergic input into the DMS exerts an inhibitory influence on social play behavior. Remarkably, infusion of $\mathrm{B} \& \mathrm{M}$ into the DMS only tended to increase pouncing. It is possible that inactivation of the DMS with $\mathrm{B} \& \mathrm{M}$ affects opposing processes resulting in the absence of a clear effect as observed after AMPA/kainate receptor blockade. Stated otherwise, an optimal balance of different inputs into the DMS may be necessary for proper expression of social play behavior, whereby B\&M infusion affects these inputs, as well as the activity of striatal output cells, in a comparable fashion, which results in a smaller net effect of inactivation.

We previously observed a correlation between social playinduced c-fos activity in the DMS and its inputs from the PrL (Van Kerkhof et al, 2013), suggesting that glutamatergic inputs from the PrL to the DMS are involved in social play behavior. However, inhibition of PrL output reduced social play behavior, whereas blocking glutamatergic inputs into the DMS increased it. Thus, involvement of a glutamatergic PrL-to-DMS projection in social play does not appear likely. However, as inactivation of the PrL will inhibit all its outputs, the specific involvement of the PrL-DMS projection may be overshadowed by the effect of PrL B\&M on other PrL outputs. In addition, it is possible that other glutamatergic inputs are responsible for the effects of DMS manipulation, such as those from the amygdala and thalamus. Indeed, these regions have been implicated in social play behavior (Siviy and Panksepp, 2011; Trezza et al, 2010, 2012).

Previous lesion and inactivation studies have shown involvement of the DMS in response selection (Devan et al, 1999; Corbit and Janak, 2007) and response inhibition (Eagle and Robbins, 2003). Thus, animals lacking a functional DMS display various forms of disinhibited behavior. Of particular interest are the findings that a DMS lesion impairs (Eagle and Robbins, 2003), whereas treatment with methylphenidate improve stop signal reaction time task performance (Eagle et al, 2007). These findings echo the effects of methylphenidate (Vanderschuren et al, 2008), which reduces social play, and intra-DMS DNQX, which enhances it (present study). We do not think that DMS inactivation causes an overall disinhibition of behavior. In the present study, the effects of intra-DMS DNQX on social play were behaviorally specific, as no changes were observed in social exploration and locomotor activity. Moreover, animals with DMS lesions show no change in responding for food under a progressive ratio schedule of reinforcement (Eagle et al, 1999), and operant responding remains sensitive to presentation of reward-associated stimuli after DMS inactivation (although the specificity of responding is impaired; Corbit and Janak, 2007). Together, these data suggest that DMS mechanisms exert inhibitory control over vigorous forms of behavior, such as social play, but that inactivation or lesion of the DMS leaves the structure of behavior and its appropriateness to the situation intact (Whishaw et al, 2007).

\section{Concluding Remarks}

The present study indicates a more direct involvement of the medial PFC and OFC in social play behavior than previously thought. Besides facilitating the performance of appropriate responses to play initiations from the partner, as previously reported (Bell et al, 2009; Pellis et al, 2006), functional integrity of the medial $\mathrm{PFC} / \mathrm{OFC}$ is important for the animal to initiate a playful interaction itself. Furthermore, glutamatergic inputs into the DMS exert inhibitory control over social play behavior, whereas functional inhibition of the NAcc core prolongs playful interactions. These results provide important clues to understand how the PFC and striatum are involved in social play behavior.

\section{ACKNOWLEDGEMENTS}

This study was supported by the National Institute on Drug Abuse Grant R01 DA022628 (LJMJV), Netherlands Organization for Scientific Research (NWO) Veni Grant 91611052 (VT), and Marie Curie Career Reintegration Grant PCIG09GA-2011-293589 (VT).

\section{DISCLOSURE}

The authors declare no conflict of interest.

\section{REFERENCES}

Adolphs R (2003). Cognitive neuroscience of human social behaviour. Nat Rev Neurosci 4: 165-178.

Alessandri SM (1992). Attention, play, and social behavior in ADHD preschoolers. J Abnorm Child Psychol 20: 289-302.

Baarendse PJJ, Counotte DS, O'Donnell P, Vanderschuren LJMJ (2013). Early social experience is critical for the development of cognitive control and dopamine modulation of prefrontal cortex function. Neuropsychopharmacology; e-pub ahead of print (doi:10.1038/npp.2013.47). 
Baenninger LP (1967). Comparison of behavioural development in socially isolated and grouped rats. Anim Behav 15: 312-323.

Balfour ME, Brown JL, Yu L, Coolen LM (2006). Potential contributions of efferents from medial prefrontal cortex to neural activation following sexual behavior in the male rat. Neuroscience 137: 1259-1276.

Bell HC, McCaffrey DR, Forgie ML, Kolb B, Pellis SM (2009). The role of the medial prefrontal cortex in the play fighting of rats. Behav Neurosci 123: 1158-1168.

Berridge KC, Kringelbach ML (2008). Affective neuroscience of pleasure: reward in humans and animals. Psychopharmacology 199: 457-480.

Bolles RC, Woods PJ (1964). The ontogeny of behavior in the albino rat. Anim Behav 12: 427-441.

Braun K, Bock J (2011). The experience-dependent maturation of prefronto-limbic circuits and the origin of developmental psychopathology: implications for the pathogenesis and therapy of behavioural disorders. Dev Med Child Neurol 53(Suppl 4): 14-18.

Carlezon WA Jr, Thomas MJ (2009). Biological substrates of reward and aversion: a nucleus accumbens activity hypothesis. Neuropharmacology 56(Suppl 1): 122-132.

Casey BJ, Jones RM (2010). Neurobiology of the adolescent brain and behavior: implications for substance use disorders. $\mathrm{J} \mathrm{Am}$ Acad Child Adolesc Psychiatry 49: 1189-1201.

Cheng SY, Taravosh-Lahn K, Delville Y (2008). Neural circuitry of play fighting in golden hamsters. Neuroscience 156: 247-256.

Chudasama Y, Passetti F, Rhodes SE, Lopian D, Desai A, Robbins TW (2003). Dissociable aspects of performance on the 5-choice serial reaction time task following lesions of the dorsal anterior cingulate, infralimbic and orbitofrontal cortex in the rat: differential effects on selectivity, impulsivity and compulsivity. Behav Brain Res 146: 105-119.

Corbit LH, Janak PH (2007). Inactivation of the lateral but not medial dorsal striatum eliminates the excitatory impact of Pavlovian stimuli on instrumental responding. J Neurosci 27: 13977-13981.

Crone EA, Dahl RE (2012). Understanding adolescence as a period of social-affective engagement and goal flexibility. Nat Rev Neurosci 13: 636-650.

Dalley JW, Cardinal RN, Robbins TW (2004). Prefrontal executive and cognitive functions in rodents: neural and neurochemical substrates. Neurosci Biobehav Rev 28: 771-784.

Devan BD, McDonald RJ, White NM (1999). Effects of medial and lateral caudate-putamen lesions on place- and cue-guided behaviors in the water maze: relation to thigmotaxis. Behav Brain Res 100: 5-14.

Eagle DM, Humby T, Dunnett SB, Robbins TW (1999). Effects of regional striatal lesions on motor, motivational, and executive aspects of progressive-ratio performance in rats. Behav Neurosci 113: 718-731.

Eagle DM, Robbins TW (2003). Inhibitory control in rats performing a stop-signal reaction-time task: effects of lesions of the medial striatum and d-amphetamine. Behav Neurosci 117: 1302-1317.

Eagle DM, Tufft MR, Goodchild HL, Robbins TW (2007). Differential effects of modafinil and methylphenidate on stopsignal reaction time task performance in the rat, and interactions with the dopamine receptor antagonist cis-flupenthixol. Psychopharmacology 192: 193-206.

Fritz M, El Rawas R, Klement S, Kummer K, Mayr MJ, Eggart V et al (2011). Differential effects of accumbens core vs. shell lesions in a rat concurrent conditioned place preference paradigm for cocaine vs. social interaction. PLoS One 6: e26761.

Gordon NS, Kollack-Walker S, Akil H, Panksepp J (2002). Expression of c-fos gene activation during rough and tumble play in juvenile rats. Brain Res Bull 57: 651-659.

Gourley SL, Lee AS, Howell JL, Pittenger C, Taylor JR (2010). Dissociable regulation of instrumental action within mouse prefrontal cortex. Eur J Neurosci 32: 1726-1734.
Graham KL (2011). Coevolutionary relationship between striatum size and social play in nonhuman primates. Am J Primatol 73: 314-322.

Groenewegen HJ, Uylings HBM (2010). Orginization of prefrontalstriatal projections. In: Steiner HTseng KY (eds). Handbook of Basal Ganglia Structure and Function. Academic Press: London, pp 353-365.

Hoover WB, Vertes RP (2011). Projections of the medial orbital and ventral orbital cortex in the rat. J Comp Neurol 519: 3766-3801.

Kelley AE (2004). Ventral striatal control of appetitive motivation: role in ingestive behavior and reward-related learning. Neurosci Biobehav Rev 27: 765-776.

Killcross S, Coutureau E (2003). Coordination of actions and habits in the medial prefrontal cortex of rats. Cereb Cortex 13: 400-408.

Krause M, German PW, Taha SA, Fields HL (2010). A pause in nucleus accumbens neuron firing is required to initiate and maintain feeding. J Neurosci 30: 4746-4756.

Maldonado-Irizarry CS, Swanson CJ, Kelley AE (1995). Glutamate receptors in the nucleus accumbens shell control feeding behavior via the lateral hypothalamus. J Neurosci 15: 6779-6788.

Manning MM, Wainwright LD (2010). The role of high level play as a predictor social functioning in autism. J Autism Dev Disord 40: 523-533.

Mar AC, Walker AL, Theobald DE, Eagle DM, Robbins TW (2011). Dissociable effects of lesions to orbitofrontal cortex subregions on impulsive choice in the rat. J Neurosci 31: 6398-6404.

Martin JH (1991). Autoradiographic estimation of the extent of reversible inactivation produced by microinjection of lidocaine and muscimol in the rat. Neurosci Lett 127: 160-164.

McFarland K, Kalivas PW (2001). The circuitry mediating cocaineinduced reinstatement of drug-seeking behavior. J Neurosci 21: $8655-8663$

Panksepp J (1981). The ontogeny of play in rats. Dev Psychobiol 14: 327-332.

Panksepp J, Beatty WW (1980). Social deprivation and play in rats. Behav Neural Biol 30: 197-206.

Panksepp J, Normansell L, Cox JF, Siviy SM (1994). Effects of neonatal decortication on the social play of juvenile rats. Physiol Behav 56: 429-443.

Panksepp J, Siviy SM, Normansell L (1984). The psychobiology of play: theoretical and methodological perspectives. Neurosci Biobehav Rev 8: 465-492.

Paxinos G, Watson C (2007). The rat brain in sterotaxic coordinates. Academic Press: London.

Pellis SM, Castaneda E, McKenna MM, Tran-Nguyen LT, Whishaw IQ (1993). The role of the striatum in organizing sequences of play fighting in neonatally dopamine-depleted rats. Neurosci Lett 158: $13-15$.

Pellis SM, Hastings E, Shimizu T, Kamitakahara H, Komorowska J, Forgie ML et al (2006). The effects of orbital frontal cortex damage on the modulation of defensive responses by rats in playful and nonplayful social contexts. Behav Neurosci 120: 72-84.

Pellis SM, McKenna MM (1992). Intrinsic and extrinsic influences on play fighting in rats: effects of dominance, partner's playfulness, temperament and neonatal exposure to testosterone propionate. Behav Brain Res 50: 135-145.

Pellis SM, Pellis VC (1987). Play-fighting differs from serious fighting in both target of attack and tactics of fighting in the laboratory rat Rattus norvegicus. Aggressive Behav 13: 227-242.

Pellis SM, Pellis VC (1998). Play fighting of rats in comparative perspective: a schema for neurobehavioral analyses. Neurosci Biobehav Rev 23: 87-101.

Pellis SM, Pellis VC, Dewsbury DA (1989). Different levels of complexity in the play-fighting by muroid rodents appear to 
result from different levels of intensity of attack and defense. Aggressive Behav 15: 297-310.

Pellis SM, Pellis VC (2009). The Playful Brain. OneWorld Publications: Oxford, UK.

Peters J, Kalivas PW, Quirk GJ (2009). Extinction circuits for fear and addiction overlap in prefrontal cortex. Learn Mem 16: 279-288.

Poole TB, Fish J (1975). Investigation of playful behavior in Rattus norvegicus and Mus musculus (Mammalia). J Zool 175: 61-71.

Salamone JD, Correa M (2012). The mysterious motivational functions of mesolimbic dopamine. Neuron 76: 470-485.

Schneider M, Koch M (2005). Deficient social and play behavior in juvenile and adult rats after neonatal cortical lesion: effects of chronic pubertal cannabinoid treatment. Neuropsychopharmacology 30: 944-957.

Siviy SM, Panksepp J (2011). In search of the neurobiological substrates for social playfulness in mammalian brains. Neurosci Biobehav Rev 35: 1821-1830.

Spear LP (2000). The adolescent brain and age-related behavioral manifestations. Neurosci Biobehav Rev 24: 417-463.

Špinka M, Newberry RC, Bekoff M (2001). Mammalian play: training for the unexpected. Q Rev Biol 76: 141-168.

Stratford TR, Kelley AE (1997). GABA in the nucleus accumbens shell participates in the central regulation of feeding behavior. J Neurosci 17: 4434-4440.

Taha SA, Fields HL (2006). Inhibitions of nucleus accumbens neurons encode a gating signal for reward-directed behavior. J Neurosci 26: 217-222.

Trezza V, Baarendse PJJ, Vanderschuren LJMJ (2009). Prosocial effects of nicotine and ethanol in adolescent rats through partially dissociable neurobehavioral mechanisms. Neuropsychopharmacology 34: 2560-2573.

Trezza V, Baarendse PJJ, Vanderschuren LJMJ (2010). The pleasures of play: pharmacological insights into social reward mechanisms. Trends Pharmacol Sci 31: 463-469.

Trezza V, Damsteegt R, Achterberg EJM, Vanderschuren LJMJ (2011). Nucleus accumbens mu-opioid receptors mediate social reward. J Neurosci 31: 6362-6370.

Trezza V, Damsteegt R, Manduca A, Petrosino S, Van Kerkhof LWM, Pasterkamp RJ et al (2012). Endocannabinoids in amygdala and nucleus accumbens mediate social play reward in adolescent rats. J Neurosci 32: 14899-14908.

Trezza V, Vanderschuren LJMJ (2008). Cannabinoid and opioid modulation of social play behavior in adolescent rats: differential behavioral mechanisms. Eur Neuropsychopharmacol 18: 519-530. van den Berg CL, Hol T, Van Ree JM, Spruijt BM, Everts H, Koolhaas JM (1999). Play is indispensable for an adequate development of coping with social challenges in the rat. Dev Psychobiol 34: 129-138.

van Duuren E, van der Plasse G, van der Blom R, Joosten RN, Mulder AB, Pennartz CM et al (2007). Pharmacological manipulation of neuronal ensemble activity by reverse microdialysis in freely moving rats: a comparative study of the effects of tetrodotoxin, lidocaine, and muscimol. J Pharmacol Exp Ther 323: 61-69.

Van Kerkhof LWM, Trezza V, Mulder T, Gao P, Voorn P, Vanderschuren LJMJ (2013). Cellular activation in limbic brain systems during social play behaviour in rats. Brain Struct Funct (doi:10.1007/s00429-013-0558-y).

Vanderschuren LJMJ, Spruijt BM, Hol T, Niesink RJM, Van Ree JM (1995). Sequential analysis of social play behavior in juvenile rats: effects of morphine. Behav Brain Res 72: 89-95.

Vanderschuren LJMJ, Niesink RJM, Van Ree JM (1997). The neurobiology of social play behavior in rats. Neurosci Biobehav Rev 21: 309-326.

Vanderschuren LJMJ, Trezza V, Griffioen-Roose S, Schiepers OJG, Van Leeuwen N, De Vries TJ et al (2008). Methylphenidate disrupts social play behavior in adolescent rats. Neuropsychopharmacology 33: 2946-2956.

Veeneman MMJ, Boleij H, Broekhoven MH, Snoeren EMS, Guitart MM, Cousijn J et al (2011). Dissociable roles of mGlu5 and dopamine receptors in the rewarding and sensitizing properties of morphine and cocaine. Psychopharmacology 214: 863-876.

Vertes RP (2004). Differential projections of the infralimbic and prelimbic cortex in the rat. Synapse 51: 32-58.

Voorn P, Vanderschuren LJMJ, Groenewegen HJ, Robbins TW, Pennartz CMA (2004). Putting a spin on the dorsal-ventral divide of the striatum. Trends Neurosci 27: 468-474.

Wall VL, Fischer EK, Bland ST (2012). Isolation rearing attenuates social interaction-induced expression of immediate early gene protein products in the medial prefrontal cortex of male and female rats. Physiol Behav 107: 440-450.

Wallis JD (2007). Orbitofrontal cortex and its contribution to decision-making. Annu Rev Neurosci 30: 31-56.

Whishaw IQ, Zeeb F, Erickson C, McDonald RJ (2007). Neurotoxic lesions of the caudate-putamen on a reaching for food task in the rat: acute sensorimotor neglect and chronic qualitative motor impairment follow lateral lesions and improved success follows medial lesions. Neuroscience 146: 86-97. 